\title{
Mandibular Distraction Osteogenesis for the Treatment of an Obstructive Sleep Apnea Patient with Orthognathic Anomaly: A Case Report and Literature Review
}

\author{
Metin Şençimen, Hasan Ayberk Altuğ, Timur Akçam, Fevzi Erdemci, Gürkan Raşit Bayar, \\ Handan Altuğ, Gamze Arıcı \\ Department of Oral and Maxillofacial Surgery, Gülhane Military Medical Academy, Ankara, Turkey \\ Email: garici@gata.edu.tr
}

Received 21 September 2014; revised 20 October 2014; accepted 12 November 2014

Academic Editor: Tamer Zerener, Department of Oral and Maxillofacial Surgery, Turkey

Copyright (C) 2014 by authors and Scientific Research Publishing Inc.

This work is licensed under the Creative Commons Attribution International License (CC BY).

http://creativecommons.org/licenses/by/4.0/

(c) (†) Open Access

\begin{abstract}
Objective: skeletal advancement in order to improve the airway dimensions is known as one of the most effective surgical theraphy for treating obstructive sleep apnea (OSA). Distraction osteogenesis (DO) can be a better treatment alternative in some selected cases similar to our patient. Using custom made distractors can make this technique more safe and successful. Study Design: Surgically assisted rapid palatal expansion (SARPE), bilateral intraoral mandibular distraction osteogenesis (MDO) and orthodontic treatment were tried to a 20 -year-old OSA patient with orthognathic anomaly. For mandibular distraction, custom made distractors were used. Results: The initial AHI of the patient was 23.3. At the end of the treatment it decreased to 8.7. Conclusions: Distraction osteogenesis could be a better alternative than the conventional orthognathic surgery in this kind of selected patients. Customization of the distraction devices can contribute to making this procedure safer and more successful.
\end{abstract}

\section{Keywords}

Obstructive Sleep Apnea, Distraction Osteogenesis, Custom-Made Distraction Device

\section{Introduction}

Obstructive sleep apnea (OSA) is characterized by repetitive episodes of upper airway obstruction (complete

How to cite this paper: Şençimen, M., Altuğ, H.A., Akçam, T., Erdemci, F., Bayar, G.R., Altuğ, H. and Arıcı, G. (2014) Mandibular Distraction Osteogenesis for the Treatment of an Obstructive Sleep Apnea Patient with Orthognathic Anomaly: A Case Report and Literature Review. Case Reports in Clinical Medicine, 3, 621-630.

http://dx.doi.org/10.4236/crcm.2014.311133 
and/or partial) which occurs during sleep, usually associated with a reduction in blood oxygen saturation [1]. OSA is a likely contributor to increased cardiovascular and cerebrovascular morbidity and mortality as well as excessive daytime sleepiness, fatigue, and neurocognitive deficits. If it is not treated, the mortality rate for severe OSA is approximately $30 \%$ at 15 years [2].

OSA is a multifactorial condition, and diagnosis and treatment must be individualized with multidisciplinary management. If it is related to an anatomic obstruction of the upper airway, surgical correction of the obstruction is effective and definitive, and should be considered for appropriate patients with mild, moderate, or severe OSA [3]. Most of OSA patients suffer from craniofacial abnormalities, such as mandibular hypoplasia and maxillary and mandibular transverse deficiencies. These abnormalities can affect patients' oral functions, aesthetics, and even mental status [4]. With the deeper recognition of the role of craniofacial abnormalities in the development of OSA, surgically assisted rapid palatal expansion (SARPE) and/or mandibular distraction osteogenesis (MDO) becomes inspiring treatment strategies to correct or improve craniofacial structures of OSA patients. Rapid maxillary expansion can have a beneficial effect on the nasorespiratory pattern in some studies in adolescents [5][7].

The purpose of this study was to present an effective method to treat an adult severe OSA patient with combined treatment of surgically assisted rapid palatal expansion, bilateral intraoral mandibular distraction osteogenesis, and orthodontics.

\section{Clinical Report}

\subsection{Preoperative Examination}

A 20-year-old male patient with a history of snoring and disturbed sleep was referred to the Department of Oral and Maxillofacial Surgery by Department of Ear Nose Throat (ENT) at Gulhane Military Medical Academy for surgical evaluation. His major complaints were loud snoring, witnessed apnea, excessive day time sleepiness besides the physical appearance of the jaws. His medical history did not reveal any preexisting disease. There was no evidence of alcohol and/or drug habit and smoking. His body mass index (BMI) was $18.93 \mathrm{~kg} / \mathrm{m}^{2}$. His ENT examination showed that his tonsils were normotrophic (Grade I) according to the Friedman modification, Mallampati classification was Grade I either. Following his fiberoptic nasopharyngoendoscophy had been done, he underwent overnight polysomnography and was diagnosed as moderate OSA (apnea hypopnea index [AHI] was 23.3).

The profile of the patient was very convex and he referred to Department of Orthodontics for studying on his facial skeletal morphology by cephalometric analysis. From sagittal point of view, he presented skeletal class II. It was clear that there were excessive insufficiencies in the mandible at the sagittal plane and in the maxilla at the transversal plane (Figure 1). The contribution of the craniofacial anomalies to OSA and the aesthetic expectations of the patient have evaluated. It was concluded that the combined therapy of orthognathic surgery and orthodontic treatment were obligatory for this case.

\subsection{Maxillary Surgery}

According to radiographic analysis orthodontic assessment, firstly, it was decided to apply SARPE to the maxilla. The aim of this first surgery was to expand the maxilla transversely and to achieve an acceptable occlusion which is necessary for the subsequent surgery of the mandible. Operations were performed under general anesthesia and nasotracheal fiberoptic intubation was used in all surgeries. After palatal expansion, the patient expressed a relief while sleeping and the polysomnography revealed a decrease in AHI from 23.3 to 14.2 (Figure 2).

\subsection{Mandibular Surgery}

After providing the desired expansion in the maxilla, the mandibular surgery was planned. A three-dimensional maxillomandibular solid model of the patient was constructed using computed tomography and a rapid prototype technique in Gülhane Military Medical Academy Medical Design and Production Center. The solid model was built with Z Corp 650 (Z Corporation-Burlington, USA). Custom-made intraoral distractors which are individualized to our patient were fabricated on this solid model. 8 - 9 screw holes were created on its each stabilization part. This modification increased the stability of the distractors during and after the surgery. We determined the exact position of the distractors on the model. Then, the simulation surgery was performed and the 

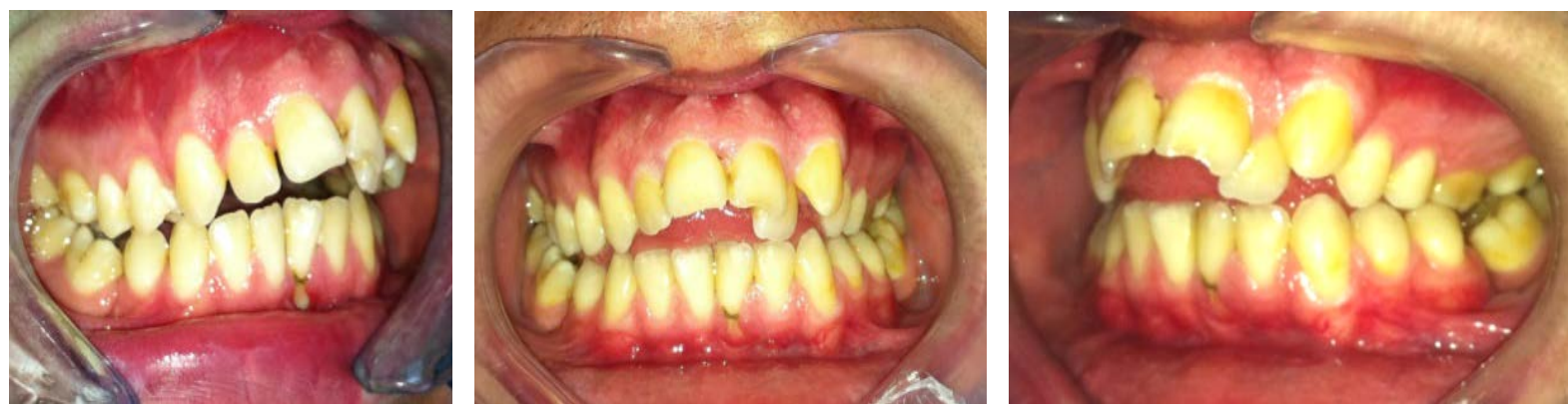

Figure 1. Intraoral view of patient before SARPE operation.

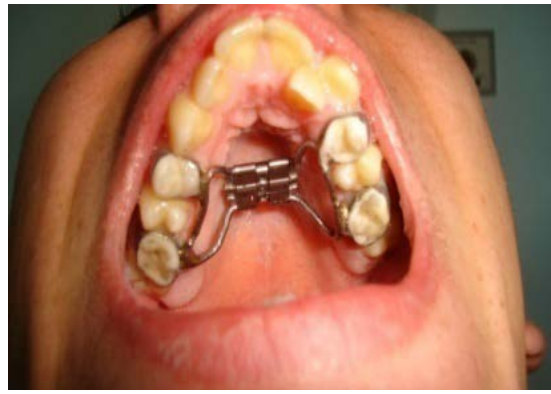

Figure 2. Intraoral view of the SARPE device.

distraction vector was controlled (Figure 3).

Before the surgery, orthodontic brackets were applied to the teeth in order to have an acceptable occlusion and provide the fixation of the mandibular surgeries (Figure 4). Two distractors were placed at both side of the mandibular corpus according to the simulated surgery on the model (Figure 5, Figure 6). It was planned to advance the mandible until an appropriate maxillomandibular relationship.

The distraction period was started at the seventh day following the surgery. Distraction rate was $0.8 \mathrm{~mm} / \mathrm{day}$. Distraction period lasted 13 days and we observed $10 \mathrm{~mm}$ distraction gap at the end of the distraction period. Active mouth opening of the patient was begun postoperatively. Distractors were kept in place for 3 months after the distraction period and then they were removed under general anesthesia (Figure 7). Two months after the removal of the distractors, 3-component of fixed prosthetic restorations were made for restoring and keeping the distraction gaps at both sides of the alveolar crests. Orthodontic treatment has been continued for 20 months. The patient is still using the retansion plaque (Figures 8-10).

During distraction period, a complication occurred. The position of the posterior arm of the distraction device on the right side of the mandible corpus could not be properly closed. Thus the osteotomy line was exposed due to the lack of nourishment and necrosis of the gingival mucosa. With a local wound care consisting of debridemant and irrigation, it healed up as secondarily (Figure 11).

The patient was very pleasant with his appearance at the end of the treatment. Cephalometry revealed that we could achieve the desired angulation and proportions (Figure 12, Figure 13, Table 1). Polysomnography findings showed that AHI decreased from 23.3 to 8.7 at the end of the treatment.

\section{Discussion}

There are several surgical treatment alternatives for the treatment of OSA. Laser-assisted uvulopalatoplasty (LAUP), uvulopalatopharyngoplasty (UPPP), hyoid suspension, tongue base reduction, genioglossus advancement and maxillomandibular advancement are the most-preferred procedures that aim to enlarge airway dimensions and decrease airway collapsibility [8]. The surgeries limited with the soft tissues (soft palate, uvula, tongue base, etc.) usually target only a spesific area of the upper airway but skeletal advancement enlarges the pharyngeal space by expanding the skeletal framework that all the soft-tissue pharyngeal structures and tongue attach to. It results in reduced pharyngeal collapsibility during negative-pressure inspiration [9]. 

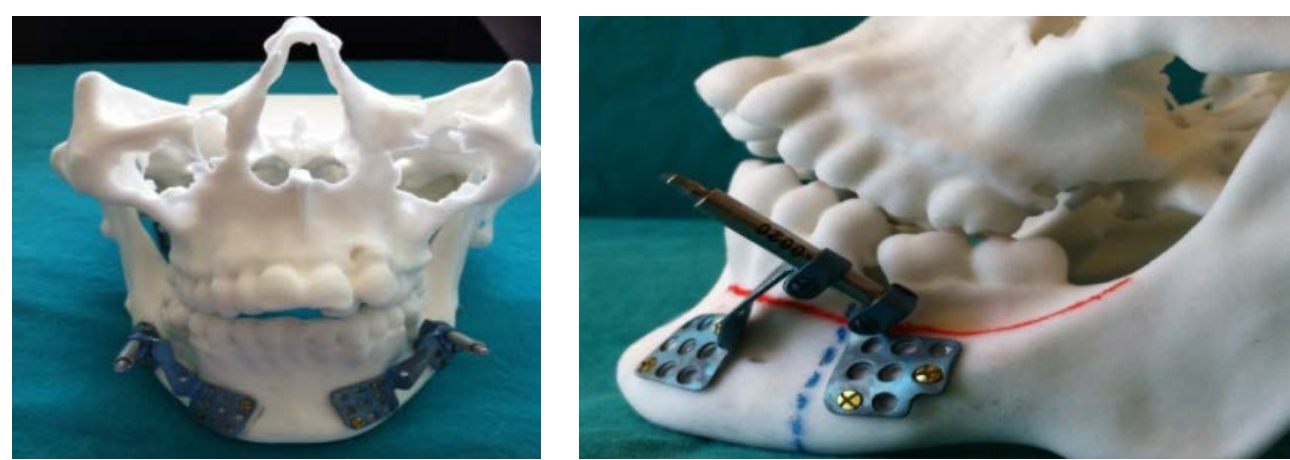

Figure 3. Distraction devices on the three-dimensional maxillomandibular solid model.

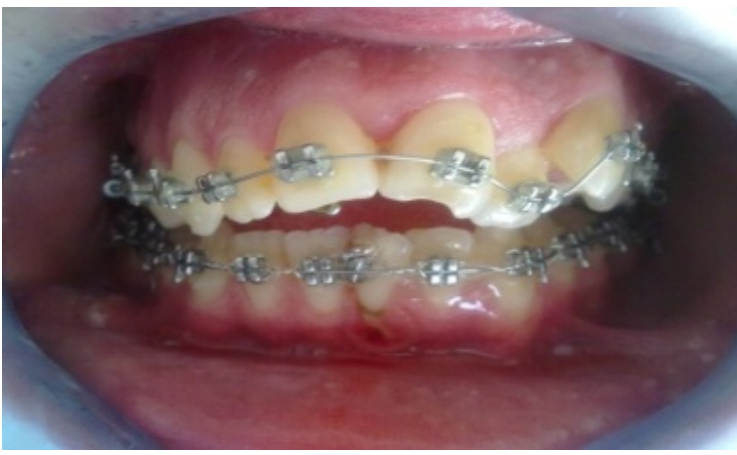

Figure 4. Intraoral appearance of the patient with orthodontic brackets before the mandibular surgery.

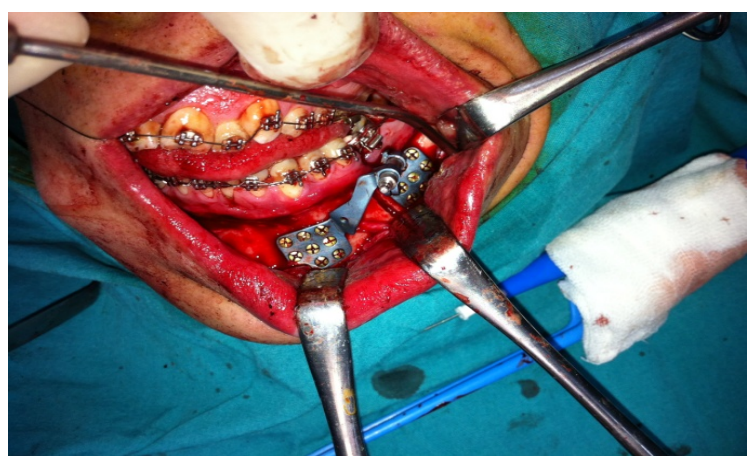

Figure 5. Intraoperative view of the mandibular surgery.

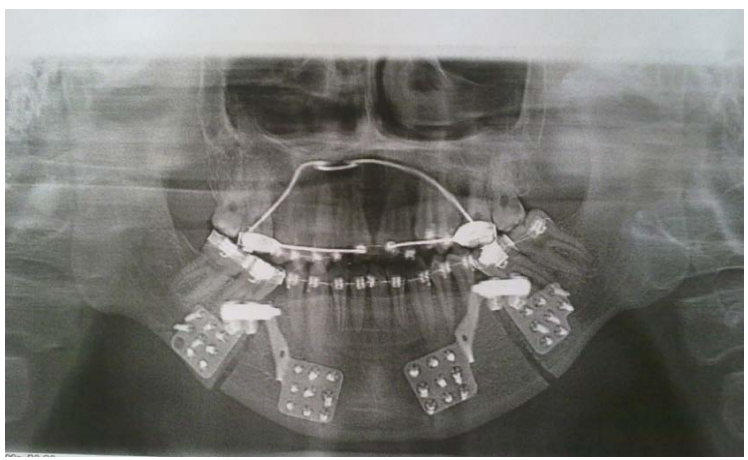

Figure 6. Postoperative panaromic radiography of the patient after mandibular corpus osteotomy. 


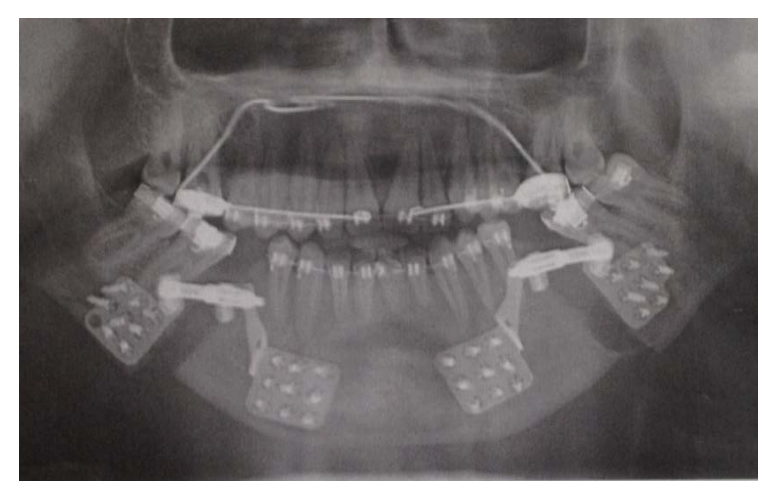

Figure 7. Panoromic radyography of the patient at the end of the distraction period.
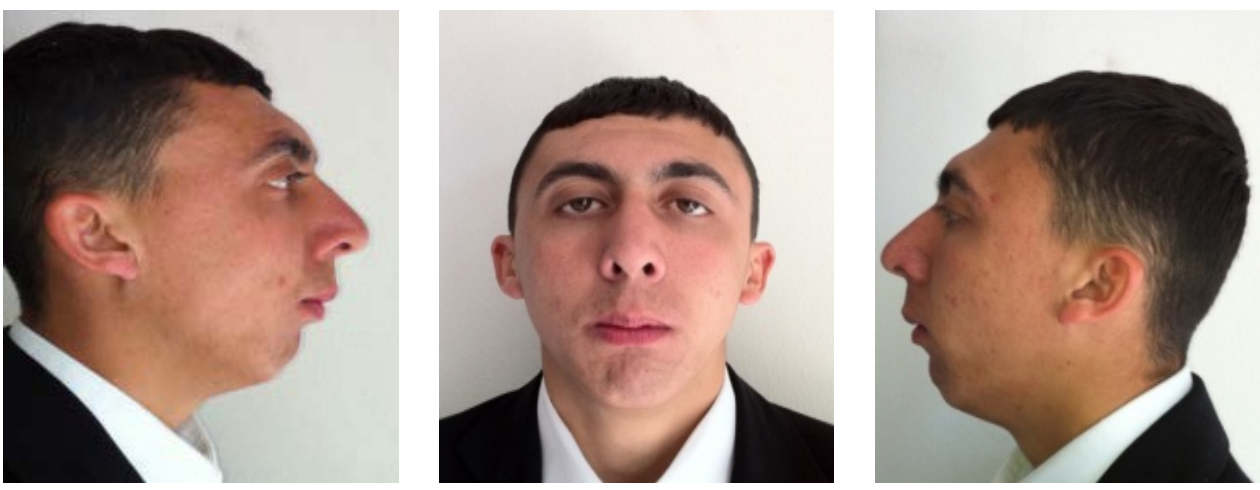

(a)
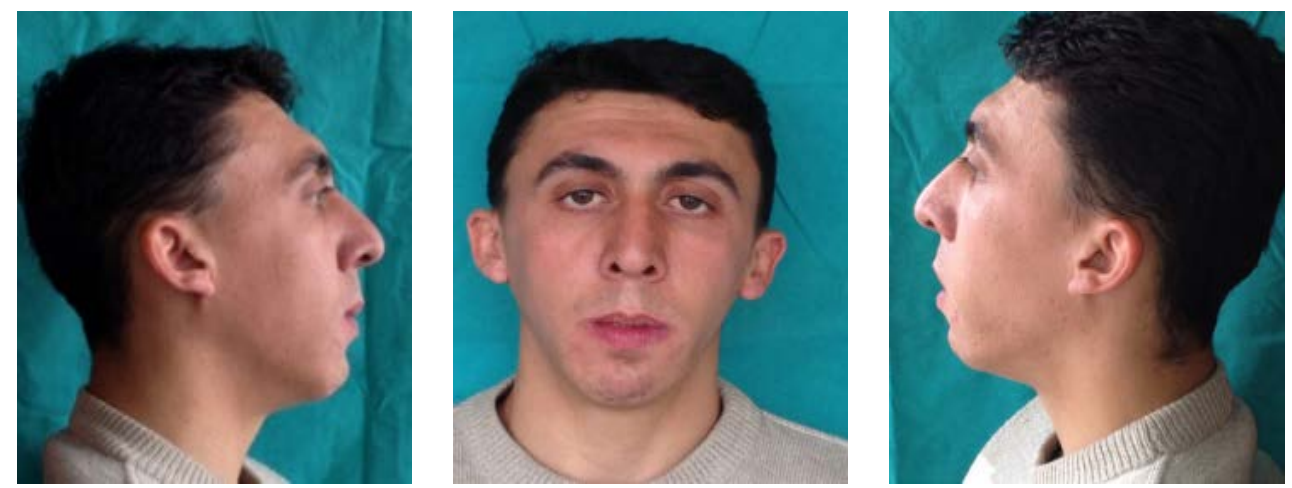

(b)

Figure 8. Preoperative (a) and postoperative (b) extraoral views of the patient after MDO surgery.
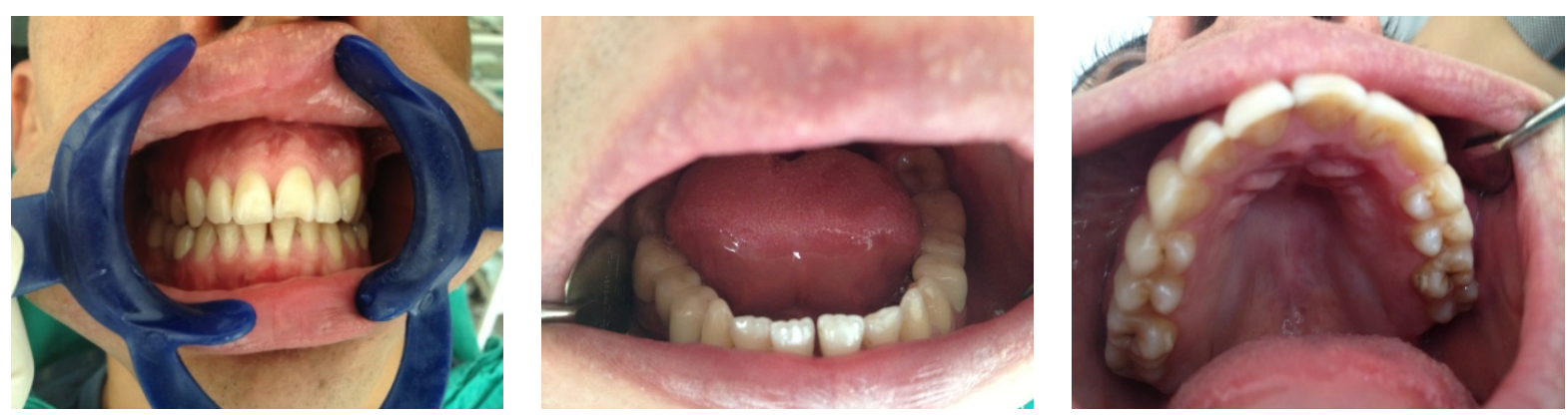

Figure 9. Intraoral views of the patient after the surgical and orthodontic treatments were completed. 


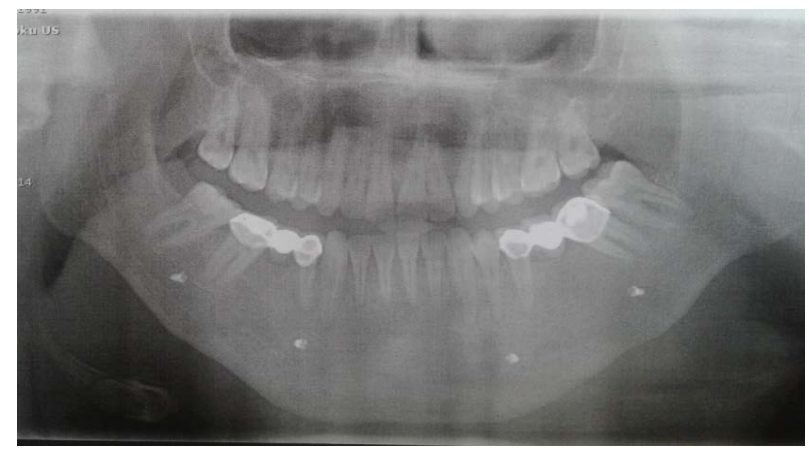

Figure 10. Final panaromic radyography of the patient.

Table 1. Cephalometric analysis of the patient.

\begin{tabular}{|c|c|c|}
\hline & Pretreatment & Posttreatment \\
\hline SNA & $76.3^{\circ}$ & $76.4^{\circ}$ \\
\hline SNB & $66.9^{\circ}$ & $71.8^{\circ}$ \\
\hline ANB & $9.4^{\circ}$ & $4.6^{\circ}$ \\
\hline S-N & $64.7 \mathrm{~mm}$ & $64.4 \mathrm{~mm}$ \\
\hline Ar-Go & $47 \mathrm{~mm}$ & $42.5 \mathrm{~mm}$ \\
\hline Y/Axis & $76.5^{\circ}$ & $74.9^{\circ}$ \\
\hline SN/ANS-PNS & $6.2^{\circ}$ & $5.9^{\circ}$ \\
\hline SN/Occ. & $23.4^{\circ}$ & $23^{\circ}$ \\
\hline SN/Go-Gn & $53.5^{\circ}$ & $52.1^{\circ}$ \\
\hline ANS-PNS/Go-Gn & $47.3^{\circ}$ & $46.2^{\circ}$ \\
\hline N-Me & $137.6 \mathrm{~mm}$ & $140.3 \mathrm{~mm}$ \\
\hline N-ANS & $56.8 \mathrm{~mm}$ & $59.2 \mathrm{~mm}$ \\
\hline ANS-Me & $80.8 \mathrm{~mm}$ & $81.1 \mathrm{~mm}$ \\
\hline S-Go & $81.1 \mathrm{~mm}$ & $81.4 \mathrm{~mm}$ \\
\hline I/SN & $108.4^{\circ}$ & $97.5^{\circ}$ \\
\hline I/Go-Gn & $92.3^{\circ}$ & $82^{\circ}$ \\
\hline $\mathrm{I} / \mathrm{I}$ & $105.8^{\circ}$ & $128.4^{\circ}$ \\
\hline I/NA & $32.1^{\circ}$ & $21.1^{\circ}$ \\
\hline I-NA & $6.4 \mathrm{~mm}$ & $5.4 \mathrm{~mm}$ \\
\hline $\mathrm{I} / \mathrm{NB}$ & $32.7^{\circ}$ & $25.9^{\circ}$ \\
\hline I-NB & $10.3 \mathrm{~mm}$ & $8.4 \mathrm{~mm}$ \\
\hline E-Line & $0.0 / 0.7 \mathrm{~mm}$ & $-3.7 / 0.3 \mathrm{~mm}$ \\
\hline Overjet & $11.2 \mathrm{~mm}$ & $5 \mathrm{~mm}$ \\
\hline Overbite & $-4.6 \mathrm{~mm}$ & $2 \mathrm{~mm}$ \\
\hline
\end{tabular}




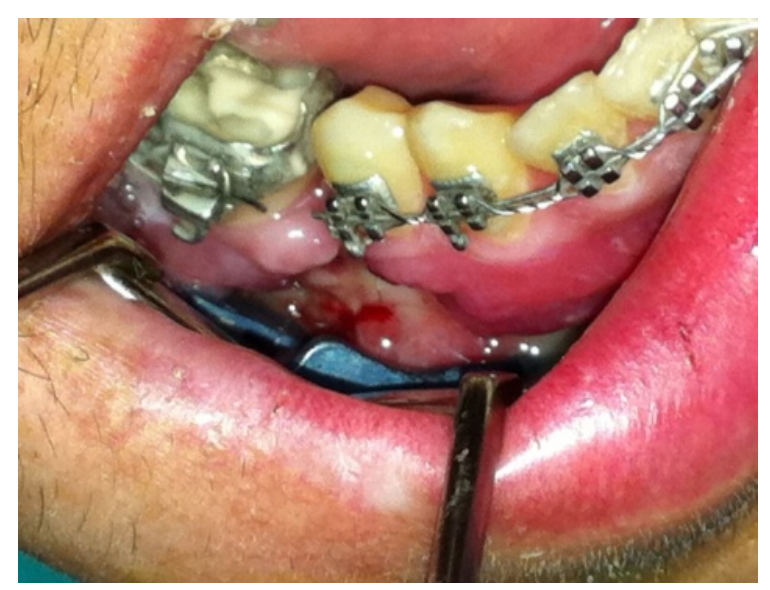

Figure 11. Exposition of the osteotomy site due to the necrosis of the gingival mucosa.

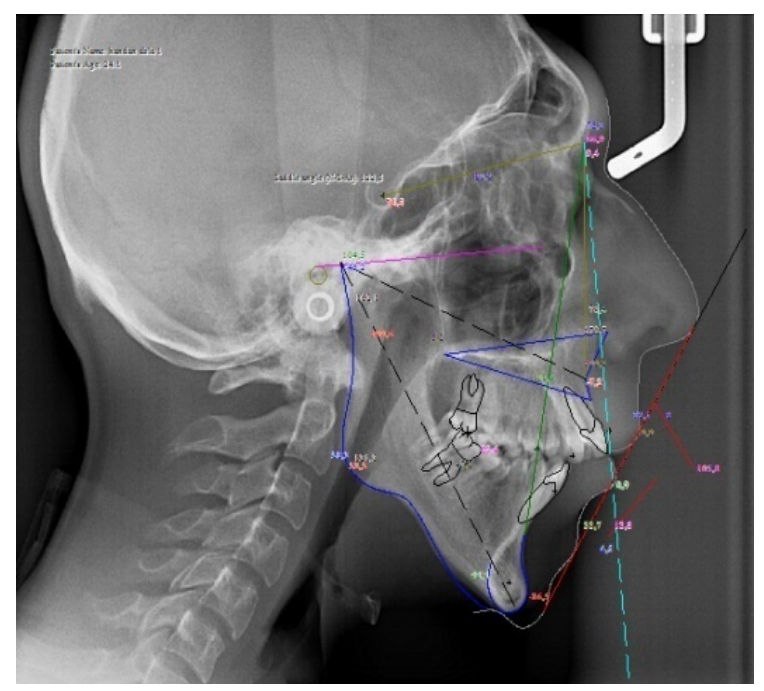

Figure 12. Preoperative cephalometry.

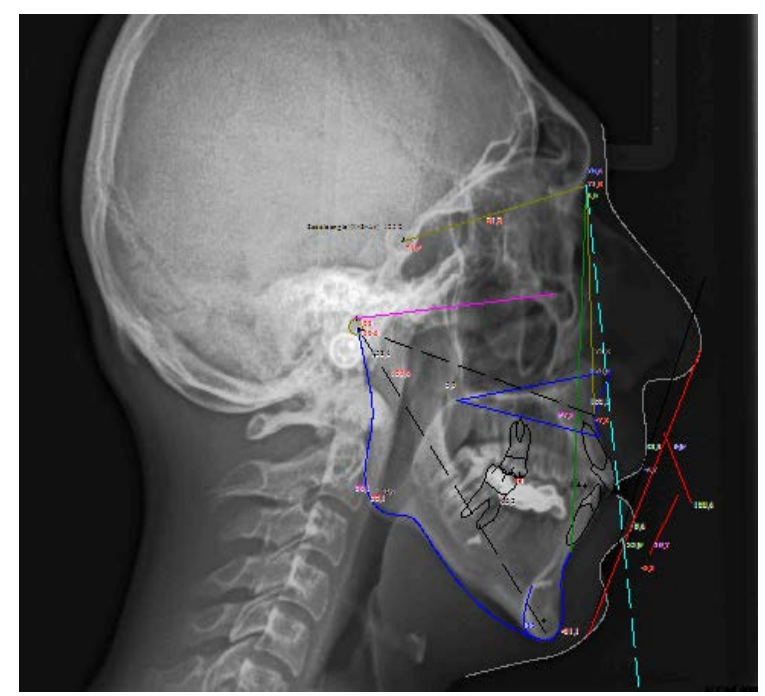

Figure 13. Postoperative cephalometry. 
The success rates of UPPP that reported by several researchers extend from 7\% to $71 \%$ [10].

Distraction osteogenesis (DO) was first introduced by Codvilla [11] and gained popularity by lenghthening the mandible in pediatric patients with hemifacial microsomia by Mc Carthy et al. [12]. It is generally accepted that the technicque can be succesfully used for the management of OSA in pediatric patients with craniofacial syndromes or deficiencies. However, there are still some controversies related to the potential application of DO in adult OSA [13] [14].

Skeletal advancement in order to improve of the airway dimensions is admitted that the most effective surgical therapy for OSA [15].

In this report, we presented the treatment of OSA in an adult patient with orthognathic anomaly with SARPE, bilateral intraoral mandibular distraction osteogenesis and orthodontics. The patient had craniofacial deficiencies that contribute his OSA and he was unpleasant with his appearance. Cephalometry, polysomnography, photographs and models were used for his initial evaulation. Consequently, it was decided to expand the maxilla first, then to advance the mandible in order to ensure a normal relationship with maxilla and cranium.

Maxillary widening helps to reduce nasal airway resistance [16]. However, there is not an agreement about how the transverse dimension varieties affect the OSA [17]. In our case, post-SARPE polysomnographic data revealed a significant reduction at AHI (Presurgical AHI was 23.3, post SARPE AHI was 14.2). Furthermore, the patient expressed a great relief while breathing.

After providing the desired expansion in the maxilla, the mandibular surgery was planned. We preferred to advance the mandible using distraction osteogenesis (DO) instead of conventional orthognathic surgery. Reasons of this treatment strategy are as follows: 1) DO permits the procedure to be halted once the desired advancement is obtained. 2) The incremental skeletal movement provides accommodation of the soft tissues and this improves the stability of the new skeletal position. 3) DO decreases the risk of the inferior alveolar nevre injury and permanent anesthesia. 4) Although it is not confirmed yet, DO can prevent temporomandibular joint damage by the adaption of the mandibular condyles [18].

Despite the advantages of DO, several significant disadvantages are present. First of all DO procedure in adult patients requires an elongated treatment time. The patient must undergo two operations (for the application and then removal of the device). The weakness of the regenerated bone and the presence of the distraction devices and arch bars significantly affect the patient's mastication and speech. The technicque has to be performed so sensitively for providing the proper alignment and parallelism of the distraction devices which is extremely important to avoid malocclusion. In order to overcome these difficulties and shorten the operation time, we precised the surgery on the 3-dimensional maxillomandibular solid model which was constructed using computed tomography and a rapid prototype technique. The locations of the distractors and the parallelism were determined exactly and the distraction vector was controlled.

Design and structure of the distraction device is usually ignored but it is critically important for the skeletal stabilization especially for the post surgical short-term period. In distraction osteogenesis, the distraction device ensures the advancement of the mandible but it contributes as fixation plaque also. Master et al. reported that relapse is the major complication of the mandibular distraction osteogenesis (64.8\% incidence) [19]. Gassman showed that relapse predominantly occurred in the first 6 weeks after mandibular advancement surgery (68\%) [20]. Komori et al. studied a method for evaluating skeletal relapsing force (SRF). They found that SRF arose not only from surgically stretched perimandibular connective tissues but also from intermittent physiologic muscle actions [21]. The source of the SRF is considered as the jaw closing muscles and the suprahyoid muscle complex [22] [23]. It is mandatory that the distraction devices must be strong and stable to resist this force. So we obtained custom-made distraction devices by rapid prototype technique which have much more screw holes in order to increase the stabilization during and after the operation.

Enfection (especially near the site of the distractors) and loosening of the distractors are common complications too [24]. We didn't observe any infection findings in our case. However, the osteotomy line on the right side of the corpus was exposed due to the necrosis of the gingival mucosa overlying on it. If it was not treated, it could be a reason for seconder infection. We applied only a local wound care. So, it healed it up as secondarily.

After surgical advancement of the mandible for $6 \mathrm{~mm}$, AHI decreased to 8.7 from 14.2 (The initial AHI score was 23.3). It was the only literature we achieved that Nie et al. used maxillary expansion and bilateral intraoral distraction osteogenesis to treat a 20-year-old male OSA patient. The initial AHI of the patient was 54.2. After surgical procedures and orthodontic treatment it decreased to 2.8 [16]. A retrospective study which is made by 56 OSA patient who underwent surgical maxillomandibular advancement revealed that the mean AHI decreased 
to 7.9 from 66.2 [2]. Skeletal advancement especially involving the mandible achieves an enlargement at posterior airway space by expanding the skeletal framework that all the soft-tissue pharyngeal structures like suprahyoid muscles (geniohyoid, digastric and mylohyoid muscles) and tongue attach to.

As far as we know, this is the only case report in the literature in which the surgical treatment of OSA consisting of SARPE and DO of the mandible by using custom-made distractors, and orthodontics.

\section{Conclusion}

We think that DO could be a better alternative than the conventional orthognathic surgery in this kind of selected patients. Some of the significant disadvantages could be overcome by using simulation technology. In addition, contribution of palatal expansion to improve OSA is not fully understood yet but this case report illustrates the benefit of increasing the transverse dimension in a patient with OSA. Further critical evaluations of this approach for the surgical treatment of OSA patients with orthognathic anomaly are needed.

\section{Acknowledgements}

We are very grateful to Osman BENGİ, the Chief of the Center of Dentistry Sciences of Gülhane Military Medical Academy, for his helps in providing us the 3D maxillomandibular solid models.

\section{References}

[1] Jones, R., Badlani, J. and Jones, C. (2010) Maxillary, Mandibular and Chin Advancement Surgery for the Treatment of Obstructive Sleep Apnoea. Australian Dental Journal, 55, 314-321. http://dx.doi.org/10.1111/j.1834-7819.2010.01241.x

[2] Holty, J.E.C. and Guilleminault, C. (2010) Maxillomandibular Advancement for the Treatment of Obstructive Sleep Apnea: A Systematic Review and Meta-Analysis. Sleep Medicine Reviews, 14, 287-297. http://dx.doi.org/10.1016/j.smrv.2009.11.003

[3] Jacobson, R.L. and Schendel, S.A. (2012) Treating Obstructive Sleep Apnea: The Case for Surgery. American Journal of Orthodontics and Dentofacial Orthopedics, 142, 435-442. http://dx.doi.org/10.1016/j.ajodo.2012.08.005

[4] Alanko, O.M., Svedström-Oristo, A.L. and Tuomisto, M.T. (2010) Patients’ Perceptions of Orthognathic Treatment, Well-Being, and Psychological or Psychiatric status: A Systematic Review. Acta Odontologica Scandinavica, 68, 249-260. http://dx.doi.org/10.3109/00016357.2010.494618

[5] Oliveira De Felippe, N.L., Da Silveira, A.C., Viana, G., et al. (2008) Relationship between Rapid Maxillary Expansion and Nasal Cavity Size and Airway Resistance: Short- and Long-Term Effects. American Journal of Orthodontics and Dentofacial Orthopedics, 134, 370-382. http://dx.doi.org/10.1016/j.ajodo.2006.10.034

[6] Pirelli, P., Saponara, M., Guilleminault, C., et al. (2004) Rapid Maxillary Expansion in Children with Obstructive Sleep Apnea Syndrome. Sleep, 27, 761-766.

[7] Marino, A., Ranieri, R., Chiarotti, F., et al. (2012) Rapid Maxillary Expansion in Children with Obstructive Sleep Apnoea Syndrome (OSAS). European Journal of Paediatric Dentistry, 13, 57-63.

[8] Sher, A., Schechtman, K. and Piccirillo, J. (1996) The Efficacy of Surgical Modifications of the Upper Airway in Adults with Obstructive Sleep Apnea Syndrome. Sleep, 19, 156.

[9] Sencimen, M., Bayar, G.R., Akçam, T., Altug, H.A., Altug, H., Gulses, A. and Ozkan, A. (2012) Management of Obstructive Sleep Apnea by Maxillomandibular Advancement Surgery in an Edentulous Patient. Journal of Craniofacial Surgery, 23, 582-583. http://dx.doi.org/10.1097/SCS.0b013e31826befe0

[10] Özgür, N. (2007) Uyku apne sendromlu ve sağlıklı bireylerin üst solunum yolu yapısal özelliklerinin araştırılması ve mandibular repositioner apareyi uygulamasının bu değerler ile uyku apne sendromu üzerine etkisinin incelenmesi. Gazi Üniversitesi Sağlık Bilimleri Enstitüsü Protetik Diş Tedavisi Anabilim Dalı Doktora Tezi, Ankara.

[11] Codivilla, A. (1905) On the Means of Lengthening, in the Lower Limbs, the Muscles and Tissues Which Are Shortened Through Deformity. The Journal of Bone \& Joint Surgery, 2.4, 353-369.

[12] McCarthy, J.G., Schreiber, J., Karp, N., Thorne, C.H. and Grayson, B.H. (1992) Lengthening the Human Mandible by Gradual Distraction. Plastic \& Reconstructive Surgery, 89, 1-8. http://dx.doi.org/10.1097/00006534-199289010-00001

[13] Cohen, S.R., Ross, D.A., Burstein, F. D., Jean-Francois, L., Frcsc, J. E. and Cathy, S. (1998) Skeletal Expansion Combined with Soft-Tissue Reduction in the Treatment of Obstructive Sleep Apnea in Children: Physiologic Results. Otolaryngology-Head and Neck Surgery, 119, 476-485. http://dx.doi.org/10.1016/S0194-5998(98)70105-6 
[14] Williams, J.K., Maull, D., Grayson, B.H., Longaker, M.T. and McCarthy, J.G. (1999) Early Decannulation with Bilateral Mandibular Distraction for Tracheostomy-Dependent Patients. Plastic \& Reconstructive Surgery, 103, 48-57. http://dx.doi.org/10.1097/00006534-199901000-00009

[15] Li, K.K., Riley, R.W., Powell, N.B., Trol, R.J. and Guilleminault, C. (1999) Overview of Phase II Surgery for Obstructive Sleep Apnea Syndrome. Ear, Nose, \& Throat Journal, 78, 851, 854-857.

[16] Nie, P., Zhu, M., Lu, X.F. and Fang, B. (2013) Bone-Anchored Maxillary Expansion and Bilateral Interoral Mandibular Distraction Osteogenesis in Adult with Severe Obstructive Sleep Apnea Syndrome. Journal of Craniofacial Surgery, 24, 949-952. http://dx.doi.org/10.1097/SCS.0b013e318286883b

[17] Conley, R.S. and Legan, H.L. (2006) Correction of Severe Obstructive Sleep Apnea with Bimaxillary Transverse Distraction Osteogenesis and Maxillomandibular Advancement. American Journal of Orthodontics and Dentofacial Orthopedics, 129, 283-292. http://dx.doi.org/10.1016/j.ajodo.2005.11.029

[18] Brevi, B.C., Toma, L., Magri, A.S. and Sesenna, E. (2011) Use of the Mandibular Distraction Technique to Treat Obstructive Sleep Apnea Syndrome. Journal of Oral and Maxillofacial Surgery, 69, 566-571. http://dx.doi.org/10.1016/j.joms.2010.09.007

[19] Master, D.L., Hanson, P.R. and Gosain, A.K. (2010) Complications of Mandibular Distraction Osteogenesis. Journal of Craniofacial Surgery, 21, 1565-1570. http://dx.doi.org/10.1097/SCS.0b013e3181ecc6e5

[20] Gassman, C.J., Van Sickels, J.E. and Thrash, W.J. (1990) Causes, Location, and Timing of Relapse Following Rigid Fixation after Mandibular Advancement. Journal of Oral and Maxillofacial Surgery, 48, 450-454. http://dx.doi.org/10.1016/0278-2391(90)90229-U

[21] Komori, E., Sagara, N. and Aigase, K. (1991) A Method for Evaluating Skeletal Relapsing Force during Maxillomandibular Fixation after Orthognathic Surgery: A Preliminary Report. American Journal of Orthodontics and Dentofacial Orthopedics, 100, 38-46. http://dx.doi.org/10.1016/0889-5406(91)70047-Z

[22] Beukes, J., Reyneke, J.P. and Becker, P.J. (2013) Medial Pterygoid Muscle and Stylomandibular Ligament: The Effects on Postoperative Stability. International Journal of Oral and Maxillofacial Surgery, 42, 43-48. http://dx.doi.org/10.1016/j.ijom.2012.05.010

[23] Carlson, D.S., Ellis III, E. and Dechow, P.C. (1987) Adaptation of the Suprahyoid Muscle Complex to Mandibular Advancement Surgery. American Journal of Orthodontics and Dentofacial Orthopedics, 92, 134-143. http://dx.doi.org/10.1016/0889-5406(87)90368-4

[24] Li, K.K., Powell, N.B., Riley, R.W. and Guilleminault, C. (2002) Distraction Osteogenesis in Adult Obstructive Sleep Apnea Surgery: A Preliminary Report. Journal of Oral and Maxillofacial Surgery, 60, 6-10. http://dx.doi.org/10.1053/joms.2002.29049 
Scientific Research Publishing (SCIRP) is one of the largest Open Access journal publishers. It is currently publishing more than 200 open access, online, peer-reviewed journals covering a wide range of academic disciplines. SCIRP serves the worldwide academic communities and contributes to the progress and application of science with its publication.

Other selected journals from SCIRP are listed as below. Submit your manuscript to us via either submit@scirp.org or Online Submission Portal.
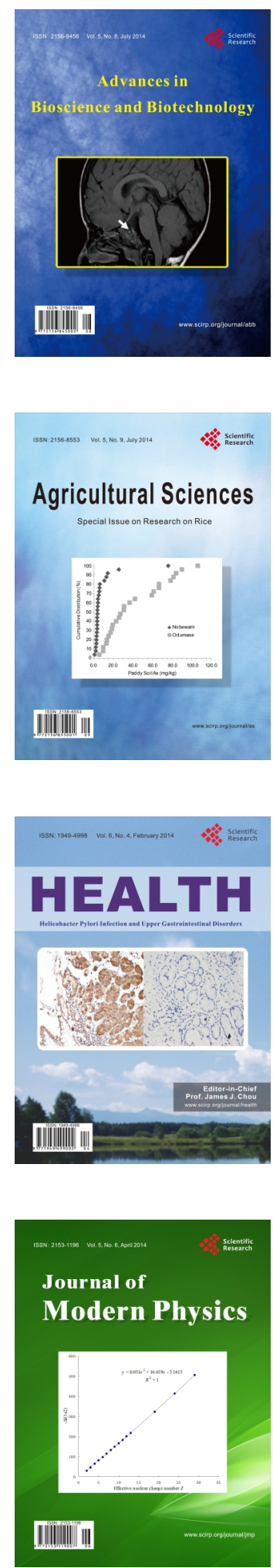
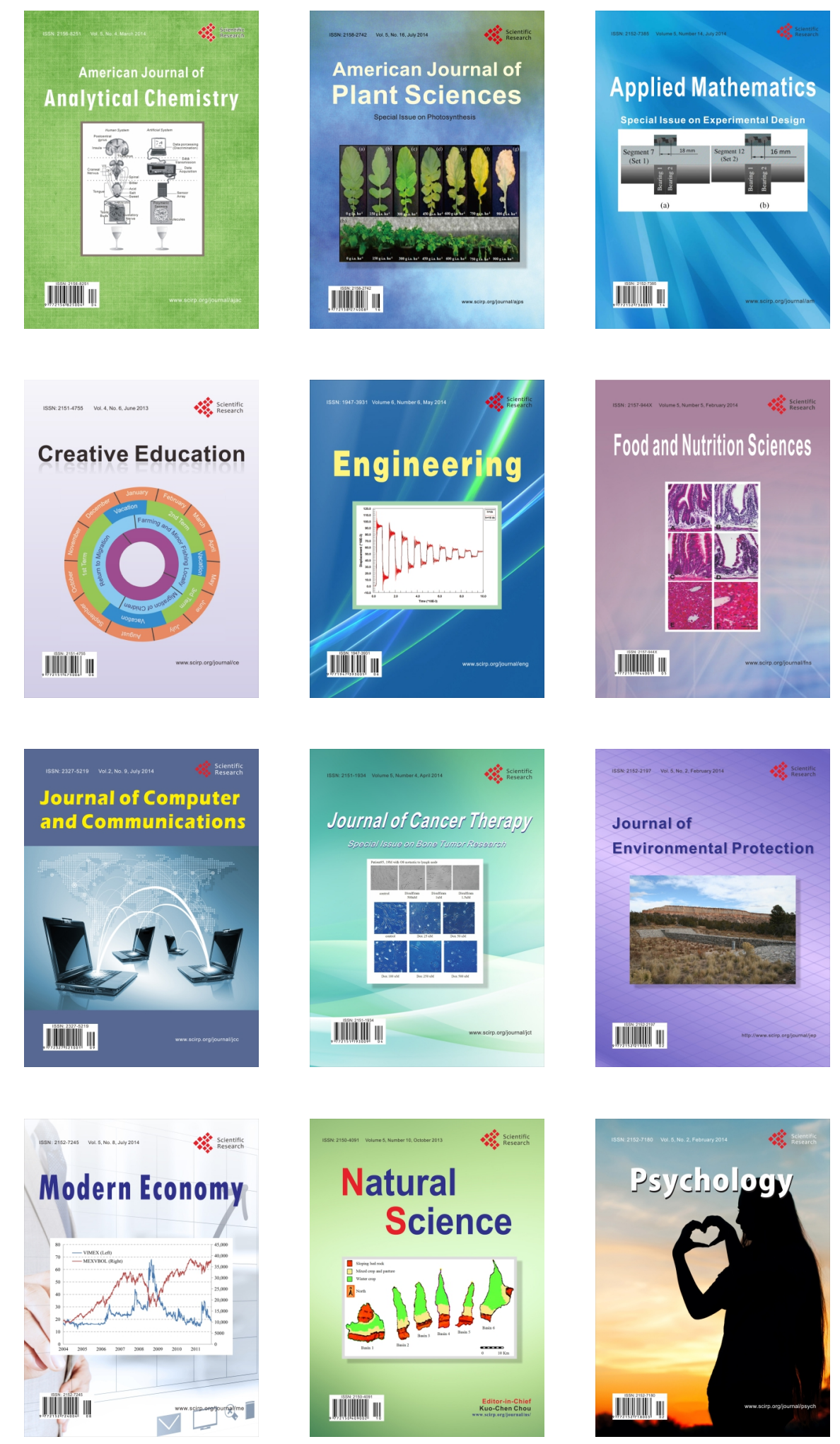